EXTENDED REPORT

\title{
Cost effectiveness of adalimumab in the treatment of patients with moderate to severe rheumatoid arthritis in Sweden
}

\author{
N J Bansback, A Brennan, O Ghatnekar
}

See end of article for authors' affiliations

....................

Correspondence to: Mr N Bansback, Health Economics and Decision Science, ScHARR, University of Sheffield, Regent Court, 40 Regent Street, Sheffield S1 4DA UK; n.j.bansback@ sheffield.ac.uk

Accepted 9 November 2004

Published Online First 18 November 2004

Background: Societal decision makers increasingly emphasise their need for evidence based economic analyses to make reimbursement decisions.

Objective: To analyse the cost utility of adalimumab, on both incremental cost and incremental quality adjusted life years (QALYs), versus traditional disease modifying antirheumatic drugs and the other tumour necrosis factor (TNF) antagonists suitable for submission to the Swedish LFN (Pharmaceutical Benefit Board).

Methods: Swedish unit costs and treatment guidelines from a lifetime perspective were implemented. A mathematical model, incorporating data from seven trials, simulated the experiences of 10000 hypothetical patients with moderate to severe rheumatoid arthritis (RA). The primary outcome measureQALYs - was derived from utility values calculated from a relationship between the Health Assessment Questionnaire (HAQ) Disability Index (DI) and Health Utility Index-III (HUI-3) from adalimumab trial results. The model followed the progression of HAQ-DI through a number of treatments in a sequence accounting for mortality, drug and monitoring costs, and other direct costs.

Results: When using ACR50 as a response threshold for determining successful treatment, adalimumab plus methotrexate showed the greatest number of QALYs gained (2.3 from one study and 2.1 from the pooled results of two trials). The etanercept plus methotrexate strategy yielded QALY gains similar to the pooled adalimumab results. Except for the infliximab strategy, the costs results were between $€ 35000$ and $€ 42000$, a range normally considered cost effective in other European countries.

Conclusion: Adalimumab appears to be cost effective for the treatment of moderate to severe RA. The results suggest that adalimumab is at least as cost effective as other TNF antagonists.

R heumatoid arthritis (RA), with an annual incidence of $1.5-2.0 \%$, is found in about 40-50000 patients in Sweden. ${ }^{1}$ The socioeconomic cost of rheumatic diseases in Sweden in 2001 has been estimated at $€ 918$ million, of which $82 \%$ is attributable to indirect costs and drugs constitute $23 \%$ of the direct medical costs. ${ }^{2}$ Another study calculated the average annual cost for a patient with RA as $€ 6600$ (1997 prices) and showed the significant extent to which costs vary depending on disease severity. ${ }^{3}$ Patients with a Health Assessment Questionnaire Disability Index (HAQ-DI) score of $>1.6$ incurred the greatest costs $(€ 18000$ a year), whereas patients with a HAQ score $<0.5$ were the least costly (€620 a year). ${ }^{3}$ Hence, if the progression of RA could be significantly inhibited, the potential for resource savings might be considerable.

The historical pharmacological treatment of RA consists of a sequence of traditional disease modifying antirheumatic drugs (DMARDs), especially methotrexate; non-steroidal anti-inflammatory drugs; and corticosteroids. However, the emergence of tumour necrosis factor (TNF) antagonists for treating moderate to severe, active RA has raised expectations for patient outcomes, transforming the management of the disease and leading rheumatologists to strive for remission. ${ }^{4}$ The most recent addition to the RA armamentarium, adalimumab (Humira; Abbott Laboratories), is a fully human monoclonal antibody with high affinity and specificity for TNF. $^{5}$ Several trials, including four phase III trials, have demonstrated the ability of adalimumab to reduce the signs and symptoms of RA, improve physical function and quality of life, and inhibit radiographic progression. ${ }^{6-10}$ With their potent clinical efficacy, and their ability significantly to inhibit radiographic progression, and fill the unmet needs of traditional DMARDs, TNF antagonists have set a new therapeutic standard. ${ }^{4}$ However, biological agents are more costly than traditional treatments, considerably increasing the resource budget for RA treatment.

Mathematical models are commonly used to assess and forecast the relative effectiveness and cost effectiveness of alternative treatment strategies. The results often guide policy decisions, assist physicians in comparing treatment strategies, and help clinicians design clinical studies. The objective of this study was to conduct a cost effectiveness analysis of adalimumab relative to different biological and non-biological DMARDs in the treatment of moderate to severe RA.

\section{PATIENTS AND METHODS Patient groups}

This analysis focused on the use of biological agents in treating patients with moderate to severe RA for whom at least two traditional DMARDs had failed. This type of patient has been studied in the majority of randomised controlled trials (RCTs) of biological agents and is most representative of the type of patient with RA receiving biological agents in Europe. We reviewed published results on the TNF

Abbreviations: ACR, American College of Rheumatology; DAS28, 28 joint count Disease Activity Index; DMARDs, disease modifying antirheumatic drugs; HAQ-DI, Health Assessment Questionnaire Disease Index; HRQoL, health related quality of life; $\mathrm{HUI}-3$, Health Utility Index-III; QALY, quality adjusted life year; RA, rheumatoid arthritis; RCTs, randomised controlled trials; TNF, tumour necrosis factor 
Table 1 A review of published trial results for TNF antagonists at 6 months

\begin{tabular}{|c|c|c|c|c|c|c|c|c|c|c|}
\hline & \multirow[b]{2}{*}{ No } & \multirow[b]{2}{*}{ Trial type } & \multirow[b]{2}{*}{$\begin{array}{l}\text { Baseline } \\
\text { HAQ }\end{array}$} & \multirow{2}{*}{$\begin{array}{l}\text { Previous } \\
\text { No of } \\
\text { DMARDs }\end{array}$} & \multirow{2}{*}{$\begin{array}{l}\text { Disease } \\
\text { duration } \\
\text { (years) }\end{array}$} & \multicolumn{5}{|c|}{$\%$ Patients responding } \\
\hline & & & & & & $\begin{array}{l}\text { Moderate } \\
\text { DAS28 }\end{array}$ & $\begin{array}{l}\text { Good } \\
\text { DAS28 }\end{array}$ & ACR20 & ACR50 & ACR70 \\
\hline \multicolumn{11}{|l|}{ Adalimumab } \\
\hline $40 \mathrm{mg}$ eow $+\mathrm{MTX}^{6}$ & 67 & $\mathrm{RCT}$ & 1.6 & 2.9 & 12.2 & 72 & 54 & 67 & 55 & 27 \\
\hline $40 \mathrm{mg}$ eow $+\mathrm{MTX}^{7}$ & 207 & $\mathrm{RCT}$ & 1.5 & 2.4 & 11.0 & 72 & 35 & 62 & 39 & 21 \\
\hline $40 \mathrm{mg} \mathrm{eow}^{8}$ & 113 & $\mathrm{RCT}$ & 1.8 & 3.8 & 10.6 & 47 & 9 & 46 & 22 & 12 \\
\hline \multicolumn{11}{|l|}{ Etanercept } \\
\hline 25 mg $2 \times$ wkly + MTX"1 & 59 & $\mathrm{RCT}$ & 1.5 & 2.7 & 13 & NA & NA & 71 & 39 & 15 \\
\hline $25 \mathrm{mg} 2 \times$ wkly $^{12}$ & 78 & $\mathrm{RCT}$ & 1.6 & 3.3 & 11 & NA & NA & 59 & 40 & 15 \\
\hline $\begin{array}{l}25 \text { mg } 2 \times \text { wkly }(46 \% \\
\text { monotherapy) }\end{array}$ & 123 & Observational & 1.6 & 4.5 & 14.9 & 46 & 31 & 60 & 37 & 11 \\
\hline \multicolumn{11}{|l|}{ Infliximab } \\
\hline $3 \mathrm{mg} / 8$ weeks $+\mathrm{MTX}^{13}$ & 86 & $\mathrm{RCT}$ & 1.8 & 2.8 & 8.4 & NA & NA & 50 & 27 & 8 \\
\hline $\begin{array}{l}3 \mathrm{mg} / 8 \text { weeks (with dose } \\
\text { increases) }+\mathrm{MTX}^{1415}\end{array}$ & 51 & Observational & 1.5 & 4.0 & 14.1 & 57 & 24 & 41 & 37 & 6 \\
\hline
\end{tabular}

eow, every other week; $2 \times$ weekly, twice weekly.

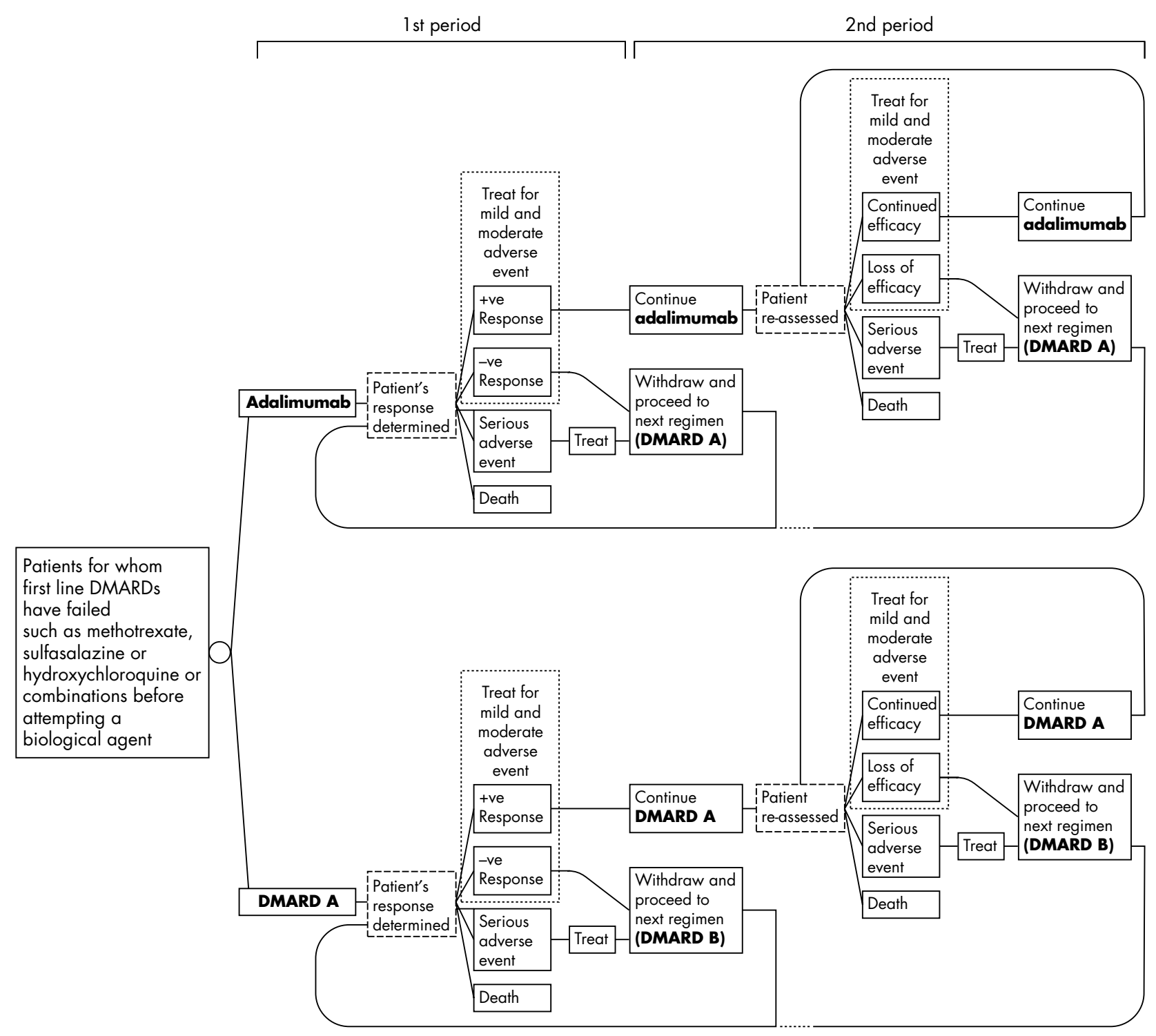

Figure 1 Diagrammatic display of a patient pathway. 
antagonists at 6 months from seven trials. ${ }^{6-8}{ }^{11-15}$ Table 1 shows that in the selected RCTs of patients with a baseline HAQ-DI of 1.5-1.6 and disease duration $>8$ years, two to four DMARDs had failed, on average. For etanercept and infliximab, these measurements are supported by an observational study conducted in Sweden. ${ }^{14}{ }^{15}$

\section{Model structure}

The mathematical approach in this analysis builds on two previously described RA models ${ }^{16}{ }^{17}$ in implementing a patient based, transition state model. This approach followed the experiences of 10000 hypothetical patients with RA. In each 6 month cycle, the risks of withdrawal, adverse event, and mortality were determined, based on the experiences of an average patient. Whenever possible, the model parameters used patient level data analysis of adalimumab RCTs or were based on reviews of epidemiology, clinical efficacy, utilities, and costs. Figure 1 shows an example of the clinical pathway for an adalimumab versus traditional DMARD comparison. The figure shows two transitions, after which the model replicates the last transition, moving to the next treatment in the sequence.

The model for the clinical pathway follows Swedish clinical practice. In patients for whom treatment shows little efficacy (based on response rates) or efficacy diminishes significantly over time, the treatment is withdrawn and a new treatment investigated..$^{18}$ Patients entered the model after first line DMARD treatments (for example, methotrexate/sulfasalazine/hydroxychloroquine/combination treatment) had failed, and it was assumed only one biological agent would be used for each patient (fig 1). After the initial biological agent was withdrawn, the patient could move on to three more DMARDs, at which point it was assumed that the patient had attempted all effective treatments and that a palliative strategy would have been introduced.

\section{Disease epidemiology \\ Response}

Treatment response evidence comes from a review of published articles and conference abstracts for licensed treatments studied in groups with moderate to severe RA (table 1). Two combination RCTs were available for adalimumab. The first trial (ARMADA) was similar to the etanercept and infliximab trials in design and patient numbers. ${ }^{6}$ The second was a larger, more comprehensive study that also included radiographic evaluations. ${ }^{7}$ Ideally, comparative results of all treatments would be available from one pragmatic trial. Until then, indirect comparisons are necessary. Such indirect comparisons are almost universal in health economic analyses, because a full assessment of all the cost consequences and health benefits of an intervention can rarely be achieved by clinical trials of safety and efficacy. ${ }^{21}$ Recommended methods of accounting for differences in patient groups between trials have been followed by adjusting for placebo rates when similar placebo strategies are used. .2-24 $^{2}$

In Sweden, decisions to continue treatment are made using the 28 joint count Disease Activity Score (DAS28) response criteria, an index that can assess the relative improvement as well as the absolute impact of new treatments. However, few RCTs have measured the DAS28, but all have measured American College of Rheumatology (ACR) response criteria. The ACR criteria, however, are only a relative measure, and, therefore, are not necessarily a realistic tool for decision making. In addition, emerging opinion suggests that the definition of therapeutic success should be made more stringent with the advent of more efficacious treatments. ${ }^{25}$ For this reason, the analysis presents results for two definitions for classifying successful response-the ACR20 and ACR50. Comparisons of trials (table 2) show that similarities in results between the ACR and DAS exist. Because the ACR response is available, it has been used to assess response. Because published DAS28 results are not available in all cases, the ACR20 version of the model assumed that an ACR20 response corresponds to a moderate DAS28 response, and the ACR50 version assumes that ACR50 corresponds to a good DAS28 response.

As some traditional DMARDs were developed more than 20 years ago, there are limited data on ACR response rates for these, especially in third and fourth line use. We deemed the

Table 2 Variables and distributions used in the model

\begin{tabular}{|c|c|c|c|c|c|}
\hline & Etanercept & Adalimumab & Infliximab & DMARDs & Distribution \\
\hline \multirow{2}{*}{$\begin{array}{l}\text { \% Response in combination dose finding trials (ACR20, ACR50, ACR70)* } \\
\% \text { Response in combination dose finding and radiographic trials } \\
(A C R 20, A C R 50, A C R 70)^{*}\end{array}$} & \multicolumn{2}{|c|}{$(66,42,19)^{11}(67,55,27)^{6}$} & $(47,29,12)^{13}$ & $(37,13,0)^{14}$ & Dirichlet \\
\hline & - & $(57,42,24)^{7}$ & - & - & Dirichlet \\
\hline$\%$ Response in monotherapy trials (ACR20, ACR50, ACR70)† & $(59,40,15)$ & ${ }^{2}(41,19,12)^{10}$ & - & - & Dirichlet \\
\hline Withdrawal during 6 months & $0.08^{15}$ & $0.08^{15}$ & $0.12^{15}$ & $0.27^{32} \ddagger$ & Beta \\
\hline \multicolumn{6}{|l|}{ Adverse events during a period of 6 months } \\
\hline Mild & $0.29^{15}$ & $0.29^{15}$ & $0.54^{15}$ & $0.34^{15}$ & Beta \\
\hline Moderate & $0.16^{15}$ & $0.16^{15}$ & $0.31^{15}$ & $0.28^{15}$ & Beta \\
\hline Serious & $0.07^{15}$ & $0.07^{15}$ & $0.1^{15}$ & $0.06^{15}$ & Beta \\
\hline \multirow[t]{6}{*}{ Monitoring and administration during the first 6 months } & $12 \mathrm{OPV}$ & $12 \mathrm{OPV}$ & $8 \mathrm{OPV}$ & $6 \mathrm{OPV}$ & Fixed \\
\hline & 1 CXR & 1 CXR & 1 CXR & $6 \mathrm{CBC}$ & \\
\hline & $13 \mathrm{CBC}$ & $13 \mathrm{CBC}$ & $13 \mathrm{CBC}$ & 6 LFT & \\
\hline & 1 LFT & 1 LFT & 1 LFT & $1 \mathrm{CMP}$ & \\
\hline & 13 CMP & 13 CMP & 13 CMP & & \\
\hline & $1 \mathrm{SIP}$ & 1 SIP & 5 INF & & \\
\hline \multirow[t]{4}{*}{ Monitoring and administration during the subsequent 6 months } & $6 \mathrm{OPV}$ & $6 \mathrm{OPV}$ & $2.5 \mathrm{OPV}$ & $6 \mathrm{OPV}$ & Fixed \\
\hline & $6 \mathrm{CBC}$ & $6 \mathrm{CBC}$ & $6 \mathrm{CBC}$ & $6 \mathrm{CBC}$ & \\
\hline & 6 LFT & 6 LFT & 6 LFT & 6 LFT & \\
\hline & & & $3.5 \mathrm{INF}$ & $1 \mathrm{CMP}$ & \\
\hline Vial size (mg) & 25 & 40 & 100 & Random sample & Fixed \\
\hline Vial cost (SEK) & 1408.5 & 5618 & 4695 & & Fixed \\
\hline Dosage & $\begin{array}{l}25 \mathrm{mg} \\
2 \times \text { wkly }\end{array}$ & $40 \mathrm{mg}$ eow & $\begin{array}{l}3 \mathrm{mg} / \mathrm{kg} \text { every } \\
8 \text { weeks }\end{array}$ & & Fixed \\
\hline \multicolumn{6}{|c|}{$\begin{array}{l}{ }^{*} \text { Trial treatment }(T T) \text { recalculated to a reference placebo }(R P) \text { equal to }(15,8,5)^{6} \text { using the trial placebo }(T P) \text { and the formula: adjusted response }=R P+\{(1-R P) \times \\
([T T-T P] /[1-T P])\} ; \text { trecalculated to a reference placebo equal to }(11,5,1)^{11} \text { using same formula; } ¥ \text { median time receiving treatment }=1.4 \text { years. Assuming } \\
\text { exponential decay }\left(y=1-\mathrm{e}^{ - \pm t}\right) ; \text {; randomly sampled from leflunomide, ciclosporin or auranofin. } \\
\text { OPV, outpatient visits; CXR, chest } x \text { ray; CBC, complete blood count; LFT, liver function test; CMP, complete metabolic panel; SIP, subcutaneous injection procedure } \\
\text { demonstration; INF, infusions. }\end{array}$} \\
\hline
\end{tabular}


Table 3 Global parameters

\begin{tabular}{lll}
\hline Variable & Value in base analysis & Distribution for multivariate analysis \\
\hline Start HAQ & $1.55^{6}$ & Normal $(1.55,0.61)$ \\
Utility/HAQ regression gradient & $0.76-0.28 \mathrm{HAQ}^{34}$ & Bivariate normal $(0.76,0.023,-0.28,0.003,-0.6)$ \\
$\mathrm{HAQ}$ progression due to no response & $0.066^{17}$ & Triangular $(0.016,0.035,0.066)$ \\
$\mathrm{HAQ}$ progression: response to DMARD & $0.017^{17}$ & Normal $(0.017,0.02)$ \\
$\mathrm{HAQ}$ progression: response to biological agent & $0.017^{17}$ & Triangular $(0,0.016,0.017)$ \\
$\mathrm{HAQ}$ direct cost regression (SEK) & $119210-1416 \mathrm{HAQ}^{3}$ & Bivariate normal $(191910,461,-1416,421,0.6)$ \\
Response decrease OR & $0.98^{26}$ & Normal $(0.98,0.0045)$ \\
Relative risk of mortality due to RA & $1.63^{40}$ & Normal $(1.63,0.14)$ \\
\hline
\end{tabular}

most relevant data to be from an observational study of etanercept, infliximab, and leflunomide, in which four DMARDs on average had failed for patients in the leflunomide arm. ${ }^{14}{ }^{15}$ From this source, we assumed that all DMARDs in the sequence have about the same response rate as leflunomide. All response rates are influenced negatively by disease duration (odds ratio of 0.98 for each extra year of disease duration). ${ }^{26}$

\section{HAQ-DI progression}

The HAQ-DI is a validated measure of assessing the short term response to treatment and a strong predictor of future disability and health related quality of life (HRQoL)..$^{28}$ This model expands upon the calculation of the initial HAQ-DI improvement, and exact workings of disability in the model have been well described by Brennan et al ${ }^{17}$ Improvements in the HAQ for responders are unpublished for most trials. Because the HAQ-DI is one of seven measures used to calculate the overall ACR response, analysis of patient level adalimumab data shows that patients who are ACR20 responders, but not ACR50 responders, have an HAQ improvement of $37 \%$ (close to the mid-point between $20 \%$ and $50 \%$ ). Similarly, for ACR50 responders who are not ACR70 responders, HAQ scores improved by $60 \% .^{67}$

An important model assumption relates to the HAQ worsening of patients after withdrawing from treatment. Little evidence exists on the long term sustained benefit of DMARDs after they have been withdrawn. Evidence from etanercept suggests that a "rebound" occurs when treatment is withdrawn. ${ }^{17}$ Thus, HAQ worsening has been assumed, perhaps conservatively, to occur immediately at the point of withdrawal, and to equal the initial HAQ improvement for all treatments. ${ }^{17}$

Long term HAQ-DI progression for this patient group is emerging. Previous economic analyses of biological agents used databanks to forecast these epidemiological profiles. However, these data were derived from mixtures of patient groups not representative of patients with longstanding moderate to severe RA. ${ }^{30}$ The limited knowledge on progression rates is incorporated in the uncertainty of parameters used in the model. Central estimates have been found from published reports,$^{17}$ but the probability distributions have integrated all plausible ranges (tables 2 and 3).

\section{Adverse events}

The long term safety of biological treatments is still to be determined, but the limited data on occurrence of mild, moderate, and serious adverse events are estimated from an observational study. ${ }^{15}$

\section{Long term withdrawal}

At each 6 month period, patients who initially responded to treatment were assessed for sustained efficacy or toxicity. The probability of withdrawal was taken from an observational study and a review of drug treatment failures. ${ }^{15} 32$

Table 4 Modelled lifetime cost breakdown of different strategies (all values in euros)

\begin{tabular}{|c|c|c|c|c|c|c|c|}
\hline & $\begin{array}{l}\text { Adalimumab } \\
+ \text { MTX (DE009) }\end{array}$ & $\begin{array}{l}\text { Adalimumab } \\
+ \text { MTX } \\
\text { (DE009 and } \\
\text { DE019) }\end{array}$ & $\begin{array}{l}\text { Etanercept } \\
+ \text { MTX }\end{array}$ & $\begin{array}{l}\text { Infliximab } \\
+ \text { MTX }\end{array}$ & $\begin{array}{l}\text { Adalimumab } \\
\text { monotherapy }\end{array}$ & $\begin{array}{l}\text { Etanercept } \\
\text { monotherapy }\end{array}$ & $\begin{array}{l}\text { Traditional } \\
\text { DMARDs }\end{array}$ \\
\hline \multicolumn{8}{|l|}{ ACR50/DAS28 good } \\
\hline Drug & 48948 & 41407 & 41140 & 29859 & 24706 & 39423 & 3962 \\
\hline Direct & 39317 & 40479 & 41271 & 48863 & 44153 & 41507 & 46145 \\
\hline Monitoring/adverse events & 20717 & 20723 & 20718 & 23376 & 21199 & 21491 & 20280 \\
\hline Total cost & 108982 & 102610 & 103129 & 102099 & 90058 & 102421 & 70387 \\
\hline Total QALY & 2.3114 & 2.1045 & 2.0974 & 1.8379 & 1.6551 & 2.0493 & 1.1818 \\
\hline Incremental cost $v$ traditional DMARD & 38595 & 32222 & 32742 & 31711 & 19671 & 32034 & - \\
\hline \multirow{2}{*}{$\begin{array}{l}\text { Incremental QALY } v \text { traditional DMARD } \\
\text { Incremental cost per QALY } v \text { traditional } \\
\text { DMARD }\end{array}$} & 1.1296 & 0.9227 & 0.9156 & 0.6560 & 0.4733 & 0.8675 & - \\
\hline & 34167 & 34922 & 35760 & 48333 & 41561 & 36927 & - \\
\hline \multicolumn{8}{|l|}{ ACR20/DAS28 moderate } \\
\hline Drug & 61306 & 56853 & 65517 & 44247 & 43860 & 55042 & 5816 \\
\hline Direct & 36246 & 37186 & 44611 & 45371 & 48721 & 36988 & 43218 \\
\hline Monitoring/adverse events & 20428 & 20424 & 23462 & 25114 & 23861 & 20320 & 19724 \\
\hline Total cost & 117979 & 114462 & 133590 & 114732 & 116442 & 112351 & 68757 \\
\hline Total QALY & 2.9083 & 2.7424 & 2.9515 & 2.4121 & 2.4321 & 2.7303 & 1.7041 \\
\hline \multirow{3}{*}{$\begin{array}{l}\text { Incremental cost } v \text { traditional DMARD } \\
\text { Incremental QALY } v \text { traditional DMARD } \\
\text { Incremental cost per QALY } v \text { traditional } \\
\text { DMARD }\end{array}$} & 49221 & 45705 & 64832 & 45974 & 47685 & 43593 & - \\
\hline & 1.2042 & 1.0383 & 1.2474 & 0.7080 & 0.7280 & 1.0262 & - \\
\hline & 40875 & 44018 & 51976 & 64935 & 65499 & 42480 & - \\
\hline
\end{tabular}




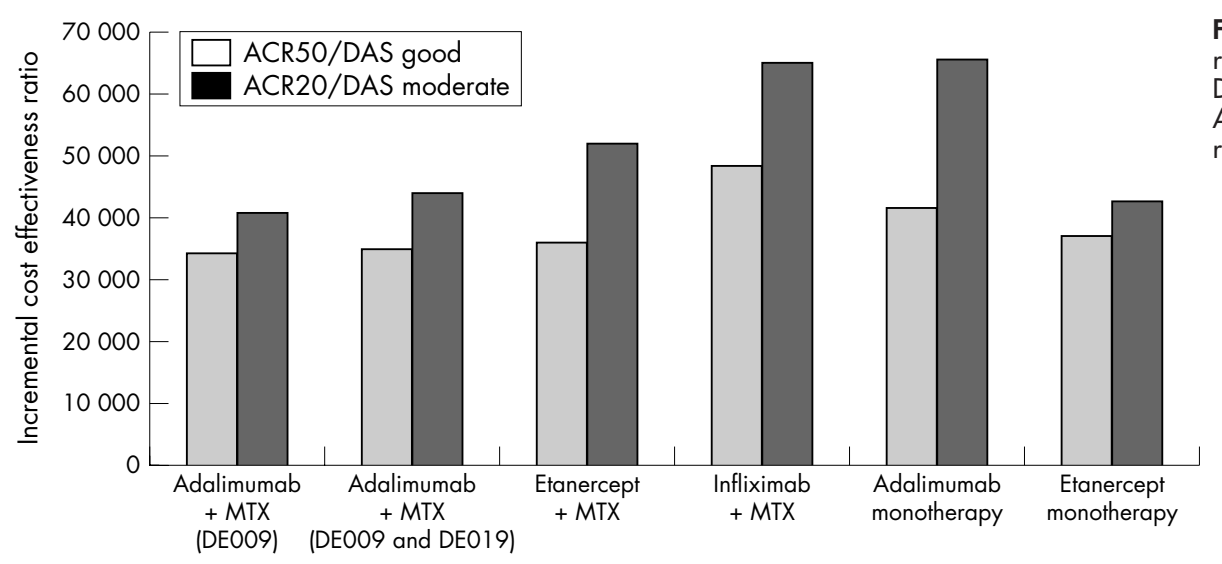

Figure 2 Incremental cost effectiveness results of all treatments $v$ traditional DMARDs for ACR50/DAS28 good and ACR20/DAS28 moderate response rates.

Health related quality of life

At each 6 month point in the model, the patients' HRQoL scores were evaluated by simple linear transformation from the HAQ-DI score. This made a cost-utility analysis possible, and, by combining HRQoL with life expectancy, produced a quality adjusted life year (QALY), single index utility. All adalimumab trials used the Health Utility Index-III (HUI-3) as an indirect measure of health utility. ${ }^{33}$

An analysis of adalimumab trial data of almost 2000 patients permitted transformation from HAQ to HUI-3 (HUI-3 utility $=0.76-0.28 \times$ HAQ-DI+0.05 $\times$ FEMALE, $R^{2}=$ 0.49). ${ }^{34}$ This transformation was necessary because the etanercept and infliximab trials did not report any health utility measures. In addition, the HUI-3 has been validated as a good measurement for severe diseases. ${ }^{35}$

\section{Resource use}

The costs of the drug, monitoring and administration, toxicity, and inpatient care are reported in 2001 euros. The annual costs of adalimumab and etanercept were equivalent at $€ 16188$, while the annual cost of infliximab decreased from $€ 13305$ to $€ 10964$ after the first year because more frequent infusions were assumed for the initial 6 months of treatment. Monitoring and treatment schedules for adverse events were determined from clinical experts and are described in table 2. For all DMARDs, traditional and biological, higher administration costs were incurred for initiating treatment than for continued or maintenance use. The total cost for time receiving any treatment was modelled as a higher initiation cost, followed by a steady annual usage cost.

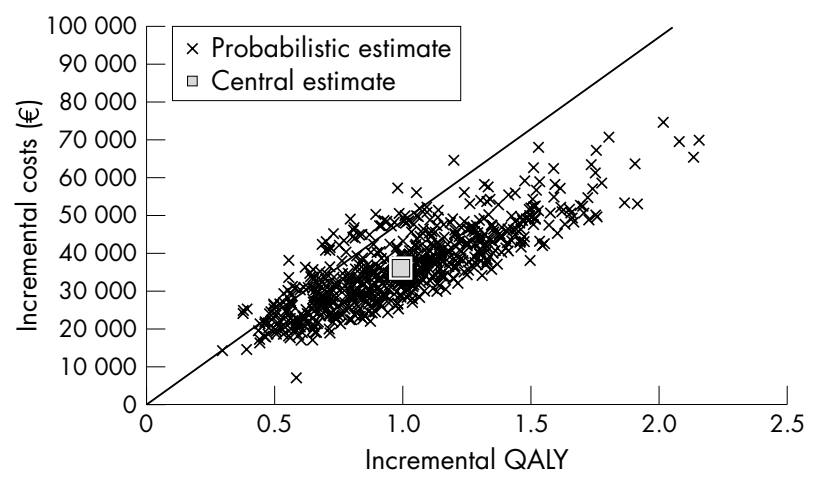

Figure 3 Cost effectiveness plane of adalimumab plus $M_{T X}{ }^{8} v$ DMARDs using an ACR50 threshold.
Other healthcare resource utilisation, such as hospital admissions and joint replacements, was estimated using approximations based on patient HAQ-DI scores. Consequently, if a patient's HAQ-DI was estimated to have improved, the patient's corresponding healthcare costs were assumed to have decreased. Many studies have shown that severe disability is positively and linearly related to inpatient resources. ${ }^{36-38}$ After transforming the cost per inpatient day from the reported Swedish $\mathrm{Kr} 3200$ to a current level of $\mathrm{Kr} 3850$, we used weighted linear regressions of the Swedish analysis. ${ }^{3}$ Excluded from the analysis are patient borne costs, social care, and productivity owing to limitations in quality data.

\section{Other parameters}

Natural mortality is incorporated into the model by means of standard life tables for a Swedish population and adjusted for standardised mortality ratios for patients with RA. ${ }^{39} 40$ Although emerging evidence suggests that improved HAQDI is associated with a lower risk of mortality, definitive evidence on the impact of biological agents on mortality has yet to be established, and no such benefit is incorporated into the model for any of the treatments. Costs and healthcare benefits were discounted at 3\% a year in line with Swedish guidance. ${ }^{41}$

\section{Analysis}

For each TNF antagonist, the incremental cost and QALYs were compared. The resulting cost effectiveness ratio can be used to make indirect comparisons between treatments. Decision makers often make a positive decision if the ratio is under a given threshold. The results have been analysed twice for adalimumab plus methotrexate. Firstly, a comparison was made using similar studies of the TNF antagonists. ${ }^{6}{ }^{11-13}$ This was followed by a second comparison that also included additional information from the larger adalimumab trial in a pooled analysis. ${ }^{7}$ Doses of infliximab other than $3 \mathrm{mg} / \mathrm{kg}$ every 8 weeks were not analysed, as the higher doses seen in the RCT provided little additional benefit at a substantial further cost.

Uncertainty in clinical and cost estimates was handled by using both central values and probability density functions to describe the distribution of uncertainty (tables 2 and 3). A univariate sensitivity analysis and multivariate sensitivity analysis were employed. The uncertainty in assumptions around model structure was also explored, particularly on methods for adjustments for comparability of trial results.

\section{RESULTS}

The model calibrated well with published 24 week QALY gains from the adalimumab trials (0.061 modelled $v 0.067$ 


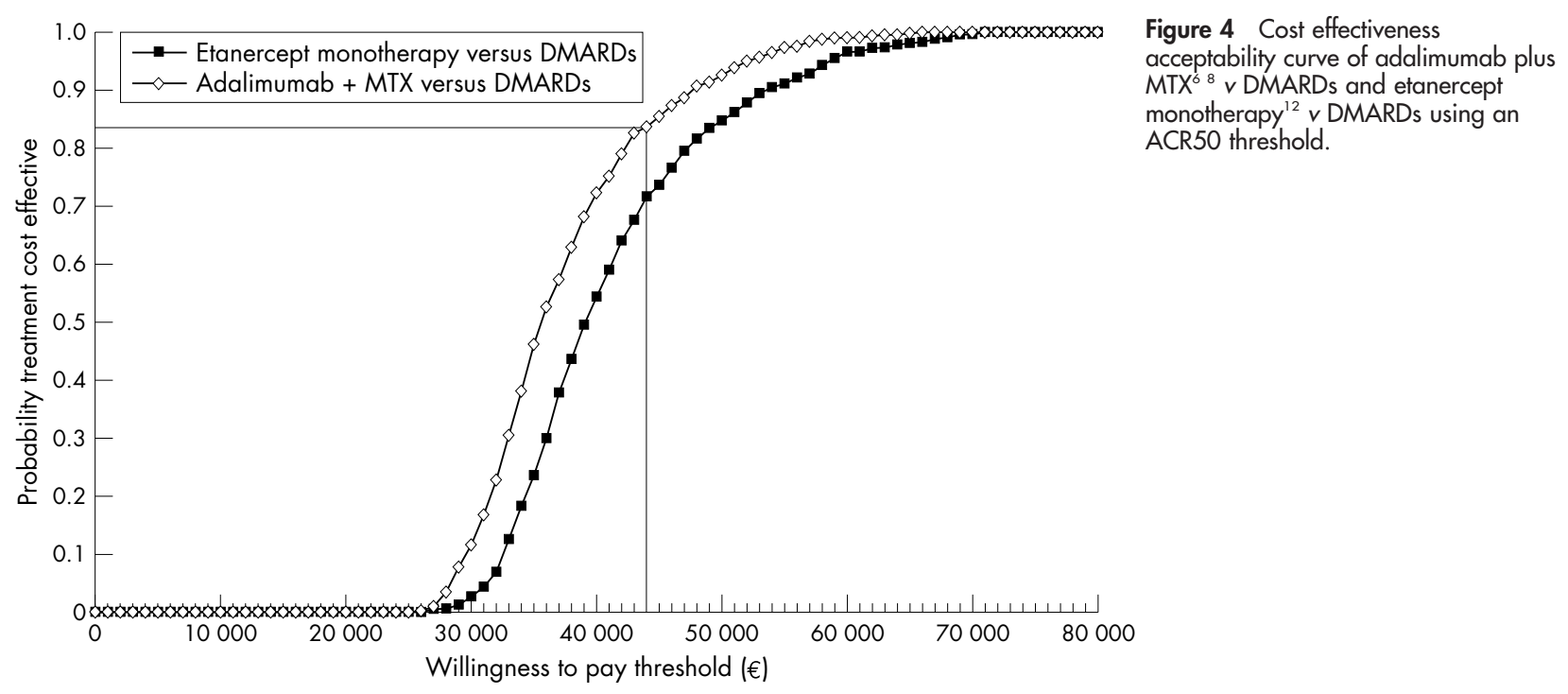

actual). ${ }^{42}$ Table 4 reports the estimated lifetime mean costs and QALYs for each strategy. The total costs resulting from the ACR20 analysis are greater than those from the ACR50 analysis, as more patients are deemed responders at 6 months and, therefore, continuing to receive treatment longer. In the ACR50 analysis, adalimumab plus methotrexate shows the greatest number of QALYs gained (equal to 2.3 and 2.1). The etanercept plus methotrexate strategy shows QALY gains similar to the pooled adalimumab results. Figure 2 shows the incremental cost effectiveness analyses in comparison with DMARDs. The results for all comparisons are concentrated between $€ 35000$ and $€ 50000$. Although no definitive willingness to pay threshold has been established in Sweden, the results are in a range normally considered cost effective in other European countries. ${ }^{43}$ The results in the ACR20 analysis are similarly concentrated.

The interactions between the uncertain parameters were assessed by sampling 1000 times with the parameters' probability density functions using a Monte Carlo simulation. Figure 3 shows a graphical representation of the incremental costs and QALYs for adalimumab plus methotrexate. ${ }^{67}$ The majority of simulations in both figures fall to the right of the line, which indicates a possible willingness to pay threshold (assumed to equal $€ 44000 / £ 30000$ ). In the scatter plot there is a clear relationship between incremental cost and QALY. Patients who continue to receive TNF antagonist treatment for substantial portions of their lives achieve large benefit because of sustained HAQ-DI improvements, but at significant cost.

Figure 4 also presents the results of the probabilistic sensitivity analysis in the form of cost effectiveness acceptability curves. This shows the probability that an intervention is cost effective at different decision thresholds. At $€ 44000$ / QALY, adalimumab is cost effective in about $83 \%$ of random samples. When the same decision threshold was used, $72 \%$ samples of etanercept monotherapy were found to be cost effective.

A univariate sensitivity analysis (fig 5) shows that in the model, baseline age, the standardised mortality ratio, and HAQ-DI/utility are sensitive to the cost effectiveness.

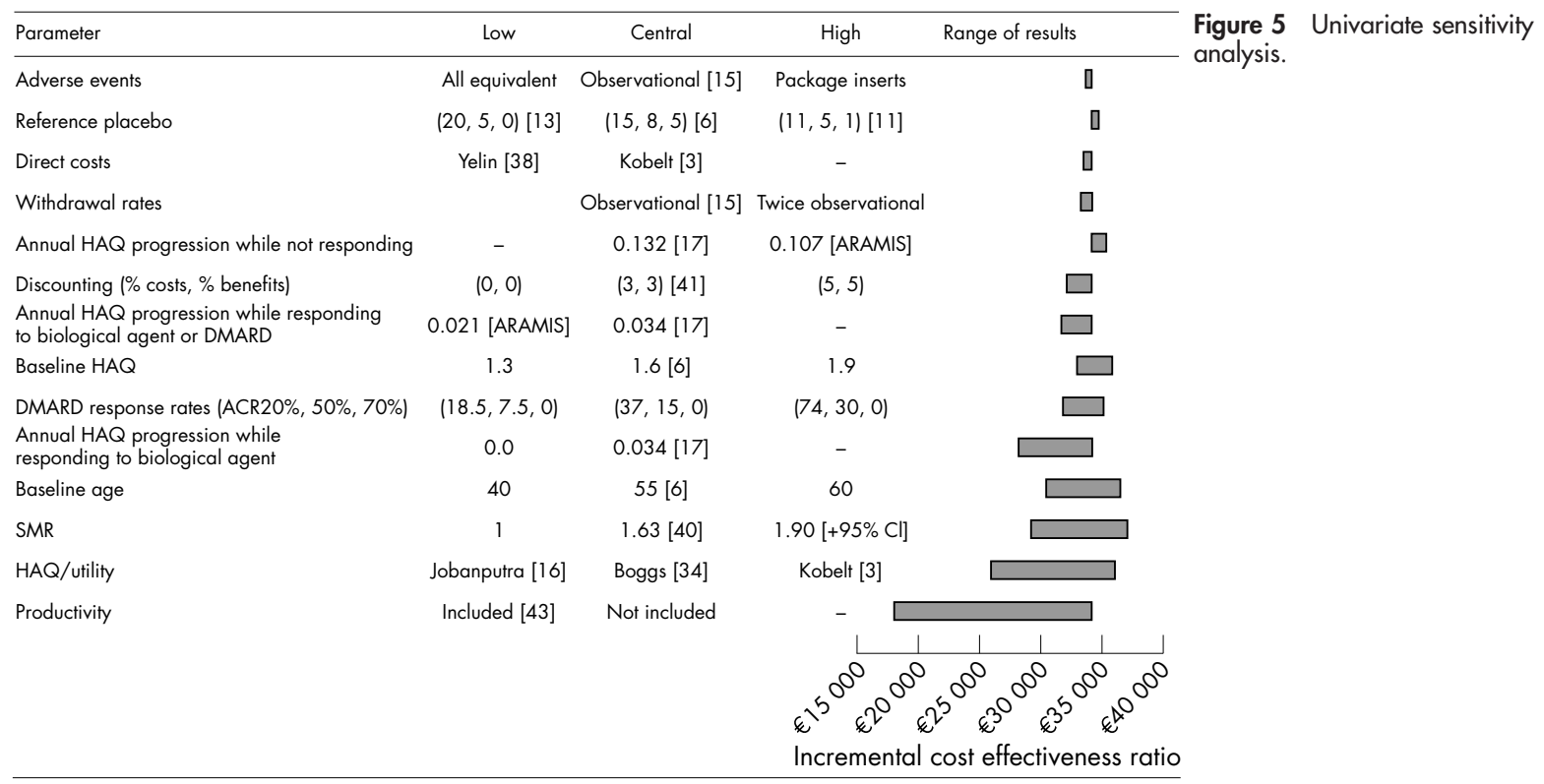




\section{DISCUSSION}

The results show that adalimumab is a cost effective treatment for moderate to severe RA. On the basis of these findings, one cannot be certain about which TNF antagonist is the most cost effective. However, because one can be more certain of the adalimumab plus methotrexate results, there is a strong argument for reimbursement of adalimumab in countries where etanercept or infliximab are already reimbursed. Incorporating the productivity losses that could be avoided in the analysis would improve the cost effectiveness of TNF antagonists further, because improved disability is related to employment status (fig 5 )..$^{44}$

Probabilistic modelling techniques are becoming standard for economic evaluations, and future studies should adhere to this method. This patient level approach allows the incorporation of feedback loops between key variables within the model, after response and withdrawal of treatment. It differs from the Markov cohort design used in two other published models of biological treatments in RA. ${ }^{31}$ The inability of standard cohort methods to handle complex models, which require patient histories, has previously been described ${ }^{45}$ In the case of RA, the "rebound" of HAQ-DI after withdrawal has not been characterised in cohort models. As each probabilistic result presented in this article required an average of 50 days to process, only two strategies were analysed. New techniques, including the Gaussian process can help eliminate first order uncertainty in patient level models to accelerate this process. ${ }^{46}$

The model is built from a policy maker's perspective, making assumptions about treatment effectiveness often beyond the time horizon of an RCT and observational evidence. This allows a policy maker to judge the long term value of implementing the new treatment. This approach contrasts sharply with the other published RA models, which allow a judgment only to be made about a policy based on only 1 or 2 years of treatment, and, regardless of efficacy, patients are withdrawn for the remainder of their lifetimes. $^{3031}$

We used the OMERACT reference case for economic evaluations in RA in developing this analysis. ${ }^{47}$ Some limitations of the availability of data within this study are identified. Firstly, indirectly comparing efficacy from different RCTs is currently a topical problem in economic evaluation. We used a simple adjustment of the placebo arms to account for differences between trial designs and patient groups. Bayesian methods for incorporating all prior knowledge, including observational trials, alternative dosing, and phase II studies, might increase certainty within the model. A second limitation is that treatment response rates drive the model-both directly, in deciding which patients continue treatment, and indirectly, through improvements in HAQ-DI scores. These response rates come from selected patients (that is, those without comorbidities and concomitant drug treatments). Rates are also derived from small patient numbers so we are uncertain of the true magnitude of efficacy as demonstrated by the overlapping confidence intervals in trial response results for biological agents. Randomised experiments of direct comparisons are required to establish superiority. Because the results of the completed studies are similar, a large sample size would be required to detect perhaps a very small difference.

Finally, the hope of reducing uncertainty in these decisions rests with observational studies and registries, but a number of problems remain. Follow up data will help quantify safety, resource use, and long term HAQ-DI trends, particularly on withdrawal. In addition, it might be possible to collect information on the relationships of quality of life and productivity. Previous studies have, however, shown the double counting in this area ${ }^{48}$ There will also be difficulties in interpreting the data, particularly in the consistency of treatment selection. The cost effectiveness of treatments used in a patient population directly correlates with the level of stringency to which the definition for success of treatment is defined, and the speed with which this is ascertained. ${ }^{19}$ For example, the cost of treating patients for whom the treatment is showing minor to moderate efficacy is the same as in a patient in whom significant efficacy is shown.

This study provides evidence of the cost effectiveness of adalimumab and TNF antagonists in patients with moderate to severe RA in Sweden. Its application to other countries needs further study. Future questions for decision makers will centre on the use of biological agents earlier in the disease course, and on rapid, intensive, sequential treatment. ${ }^{49}$ This developed model can be updated when new evidence emerges.

\section{ACKNOWLEDGEMENTS}

Financial support for this study was provided entirely by Abbott Laboratories. The funding agreement helped ensure the authors' independence in designing the study, interpreting the data, and writing and publishing the report. We are grateful to Nishan Sengupta (formerly of Abbott Laboratories), Eva Ristoff, Francis Pang, Talat Ashraf, and George MacKinnon of Abbott Laboratories for providing information necessary for the work. We also thank Michael Nissen of Abbott Laboratories for editorial assistance in the development of this manuscript.

\section{Authors' affiliations}

N J Bansback, A Brennan, Health Economics and Decision Science, School of Health and Related Research (ScHARR), University of Sheffield, UK

O Ghatnekar, Swedish Institute for Health Economics (IHE), Lund, Sweden

\section{REFERENCES}

1 Simonsson M, Bergman S, Jacobsson LT, Petersson IF, Svensson B. The prevalence of rheumatoid arthritis in Sweden. Scand J Rheumatol 1999;28:340-3.

2 Schmidt A, Husberg M, Bernfort L. Samhällsekonomiska kostnader för reumatiska sjukdomar. [Socioeconomic costs for rheumatic diseases; in Swedish only. ] Linköping: CMT Rapport 2003, 5.(ISSN 0283-1228.).

3 Kobelt G, Eberhardt K, Jonsson L. Economic consequences of the progression of rheumatoid arthritis in Sweden. Arthritis Rheum 1999;42:347-56.

4 Breedveld FC, Kalden JR. Appropriate and effective management of rheumatoid arthritis. Ann Rheum Dis 2004;63:627-33.

5 van de Putte LBA, Salfeld J, Kaymakcalan Z. Adalimumab. In: Moreland LW, Emery $P$, eds. TNF $\alpha$-inhibition in the treatment of rheumatoid arthritis. London: Martin Dunitz, 2003:71-93.

6 Weinblatt ME, Keystone EC, Furst DE, Moreland LW, Weisman MH, Birbara CA, et al. Adalimumab, a fully human anti-tumor necrosis factor a monoclonal antibody, for the treatment of rheumatoid arthritis in patients taking concomitant methotrexate. the Armada Trial. Arthritis Rheum 2003;48:35-45.

7 Keystone EC, Kavanaugh AF, Sharp JT, Tannenbaum H, Hua Y, Teoh LS, et al. Radiographic, clinical and functional outcomes with adalimumab (a human anti-TNF monoclonal antibody) in the treatment of patients with active rheumatoid arthritis on concomitant methotrexate therapy: a randomized, placebo-controlled, 52-week trial. Arthritis Rheum 2004;50:1400-11.

8 van de Putte LBA, Atkins C, Malaise M, Sany J, Russell AS, van Riel PLCM, et al. Efficacy and safety of adalimumab as monotherapy in patients with rheumatoid arthritis for whom previous disease modifying antirheumatic drug treatment has failed. Ann Rheum Dis 2004;65:508-16.

9 Furst DE, Schiff MH, Fleischmann RM, Strand V, Birbara CA, Compagnone D, et al. Adalimumab, a fully human anti-tumor necrosis factor- $\alpha$ monoclonal antibody, and concomitant standard antirheumatic therapy for the treatment of rheumatoid arthritis: results of STAR (Safety Trial of Adalimumab in Rheumatoid Arthritis). J Rheumatol 2003;30:2563-71.

10 van de Putte LBA, Rau R, Breedveld FC, Kalden JR, Malaise MG, van Riel PLCM, et al. Efficacy and safety of the fully human anti-tumour necrosis factor $\alpha$ monoclonal antibody adalimumab (D2E7) in DMARD refractory patients with rheumatoid arthritis: a 12 week, phase II study. Ann Rheum Dis 2003;62: $1168-77$.

11 Weinblatt ME, Kremer JM, Bankhurst AD, Bulpitt KJ, Fleischmann RM, Fox RI, et al. A trial of etanercept, a recombinant tumor necrosis factor receptor: $\mathrm{Fc}$ fusion protein, in patients with rheumatoid arthritis receiving methotrexate. $N$ Engl J Med 1999;340:253-9.

12 Moreland LW, Schiff MH, Baumgartner SW, Tindall EA, Fleischmann RM, Bulpitt KJ, et al. Etanercept therapy in rheumatoid arthritis. A randomized, controlled trial. Ann Intern Med 1999;130:478-86. 
13 Maini R, St Clair EW, Breedveld F, Furst D, Kalden J, Weisman M, et al. Infliximab (chimeric anti-tumour necrosis factor alpha monoclonal antibody) versus placebo in rheumatoid arthritis patients receiving concomitant methotrexate: a randomised phase III trial. ATTRACT Study Group. Lancet 1999:354:1932-9.

14 Crnkic M, Petersson I, Saxne T, Geborek P. Infiximab, etanercept and leflunomide in rheumatoid arthritis. Clinical experience in southern Sweden [abstract]. 2001. BSR conference proceedings 2001:231a.

15 Geborek P, Crnkic M, Petersson IF, Saxne T; South Swedish Arthritis Treatment Group. Etanercept, infliximab, and leflunomide in established rheumatoid arthritis: clinical experience using a structured follow up programme in southern Sweden. Ann Rheum Dis 2002;61:793-8.

16 Jobanputra $P$, Barton $P$, Bryant $S$. The effectiveness of infliximab and etanercept for the treatment of rheumatoid arthritis: a systematic review and economic evaluation. Health Technol Assess 2002;6:1-110.

17 Brennan A, Bansback N, Reynolds A, Conway P. Modelling the costeffectiveness of etanercept in adults with rheumatoid arthritis in the UK. Rheumatology (Oxford) 2004;43:62-72.

18 Fries JF. Reevaluating the therapeutic approach to rheumatoid arthritis: the "sawtooth" strategy. J Rheumatol 1990;17(suppl 22):12-15.

19 Brennan A, Bansback N. Re: Wolfe F, et al. Do rheumatology cost effectivness analyses make sense? Rheumatology (Oxford) 2004;43:677-8.

20 Sculpher M, Fenwick E, Claxton K. Assessing quality in decision analytic cost effectiveness models: a suggested framework and example of application. Pharmacoeconomics 2000; 17:461-77.

21 Buxton $M$, Drummond $M$, van Hout B, Prince R, Sheldon T, Szucs T, et al. Modelling in economic evaluation: an unavoidable fact of life. Health Econ 1997;6:217-27.

22 Song F, Altman DG, Glenny AM, Deeks JJ. Validity of indirect comparison for estimating efficacy of competing interventions: empirical evidence from published meta-analyses. BMJ 2003;326:472.

23 Choi HK, Seeger JD, Kuntz KM. A cost-effectiveness analysis of treatment options for patients with methotrexate-resistant rheuamtoid arthritis. Arthritis Rheum 2000;43:2316-27.

24 Choi HK, Seeger JD, Kuntz KM. A cost effectiveness analysis of treatment options for methotrexate-naive rheumatoid arthritis. J Rheumatol 2002;29:156-65

25 Felson DT, Anderson JJ, Lange MLM. Should improvement in rheumatoid arthritis clinical trials be defined as fifty percent or seventy percent improvement in core set measures, rather than twenty percent? Arthritis Rheum 1998;41:1564-70.

26 Anderson JJ, Wells G, Verhoeven AC, Feltelius N. Factors predicting response to treatment in rheumatoid arthritis: the importance of disease duration. Arthritis Rheum 2000;43:22-9.

27 Fries JF, Spitz P, Kraines G, Holman H. Measurement of patient outcome in arthritis. Arthritis Rheum 1980;23:37-45.

28 Wolfe F. A reappraisal of $H A Q$ disability in rheumatoid arthritis. Arthritis Rheum 2000;43:2751-61.

29 Chilcott J, Brennan A, Booth A, Karnon J, Tappenden P. The role of modelling in prioritising and planning clinical trials. Health Technol Assess 2003;7:23

30 Kobelt G, Jönsson L, Lindgren P, Young A, Eberhardt K. Modeling the progression of rheumatoid arthritis: a two-country model to estimate costs and consequences of rheumatoid arthritis. Arthritis Rheum 2002;46:2310-19.

31 Wong JB, Singh G, Kavanaugh A. Estimating the cost-effectiveness of 54 weeks of infliximab for rheumatoid arthritis. Am J Med 2002;113:400-8.

32 Wolfe $\mathbf{F}$. The epidemiology of drug treatment failure in rheumatoid arthritis. Baillieres Clin Rheumatol 1995;9:619-32.
33 Feeny D, Furlong W, Torrance GW, Goldsmith CH, Zhu Z, DePauw S, et al. Multiattribute and single-attribute utility functions for the Health Utilities Index mark 3 system. Med Care 2002;40:113-28.

34 Boggs R, Sengupta N, Ashraf T. Estimating health utility from a physical function assessment in rheumatoid arthritis (RA) patients treated with adalimumab (HUMIRA) [abstract]. International Society of Pharmacoeconomics and Outcomes Research, 2002; abstract UT3.

35 Conner-Spady B, Suarez-Almazor ME. Variation in the estimation of qualityadjusted life-years by different preference-based instruments. Med Care 2003;41:791-801

36 Leardini G, Salaffi F, Montanelli R, Gerzeli S, Canesi B. A multicenter cost-ofillness study on rheumatoid arthritis in Italy. Clin Exp Rheumatol 2002;20:505-15

37 Lajas C, Abasolo L, Bellajdel B, Hernandez-Garcia C, Carmona L, Vargas E, et al. Costs and predictors of costs in rheumatoid arthritis: a prevalence-based study. Arthritis Rheum 2003:49:64-70.

38 Yelin E, Wanke LA. An assessment of the annual and long term direct costs of rheumatoid arthritis: the impact of poor function and functional decline. Arthritis Rheum 1999;42:1209-18.

39 SCB Befolkningsstatistik 2000. Del 4. Lifetables for Sweden - 1996-2000. Statistical yearbook of Sweden. Statistics Sweden, 2002.

40 Bjornadal L, Baecklund E, Yin L, Granath F, Klareskog L Ekbom A. Decreasing mortality in patients with rheumatoid arthritis: results from a large population based cohort in Sweden, 1964-95. Rheumatology (Oxford) 2002;29:906-12

41 Läkemedelsförmånsnämnden. General guidelines for economic evaluations from the Pharmaceutical Benefits Board (LFNAR 2003:2). http://www.Ifn.se/ upload/English/ENG Ifnar2003-eng.pdf, accessed 4 March 2005.

42 Torrance GW, Tugwell P, Amorosi S, Chartash E, Sengupta N. Improvement in health utility among patients with rheumatoid arthritis treated with adalimumab (a human anti-TNF monoclonal antibody) plus methotrexate. Rheumatology (Oxford) 2004;43:712-18.

43 Rafferty J. NICE: faster access to modern treatments? Analysis of guidance on health technologies. BMJ 2001;323:1300-3.

44 Wolfe F, Hawley DJ. The longterm outcomes of rheumatoid arthritis: work disability: a prospective 18 year study of 823 patients. J Rheumatol 1998;25:2108-17.

45 Hunink MG, Bult JR, de VriesJ, Weinstein MC. Uncertainty in decision models analyzing cost-effectiveness: the joint distribution of incremental costs and effectiveness evaluated with a nonparametric bootstrap method. Med Decis Making 1998; 18:337-46.

46 Stevenson MD, Oakley J, Chilcott JB. Gaussian process modelling in conjunction with individual patient simulation modelling. A case study describing the calculation of cost-effectiveness ratios for the treatment of established osteoporosis. Med Decis Making 2004;24:89-101.

47 Maetzel A, Tugwell P, Boers M, Guillemin F, Coyle D, Drummond M, et al. Economic evaluation of programs or interventions in the management of rheumatoid arthritis: defining a consensus-based reference case. J Rheumatol 2003;30:891-6.

48 Maetzel A, Pencharz $\sqcup$, Bombardier C. How much double counting? The relationship between indirect costs and EQ-5D utilities in patients with rheumatoid arthritis (RA) [abstract]. Med Decis Making 2002;22:557.

49 Smolen JS, Sokka T, Pincus T, Breedveld FC. A proposed treatment algorithm for rheumatoid arthritis: aggressive theapy, methotrexate, and quantitative measures. Clin Exp Rheumatol 2003;21(suppl 31):S209-10. 